\title{
STRATEGI PENGEMBANGAN JAMUR TIRAM (Pleurotus Ostreatus) DI KELOMPOK TANI ANEKA JAMUR DESA GONDANGMANIS KECAMATAN KARANGPANDAN KABUPATEN KARANGANYAR
}

\author{
Nugraheni Retnaningsih, Bambang N.C \\ Universitas Veteran Bangun Nusantara Sukoharjo \\ Email : nretna@gmail.com, bambangnurcahyaningrum@gmail.com
}

\begin{abstract}
The aim of this research is to determine the most effective strategy priority to be applied in the developing oyster mushroom in Aneka Jamur Farmer Group Gondangmanis Village, Karangpandan Subdistrict, Karanganyar District. The method of location selection in this research is purposive method. The research stages including the identification of internal and external factors that show the strengths, weaknesses, opportunities and threats that is faced by the farmer groups. The input stage is implemented by IFE matrix and EFE matrix. Phase matching by using SWOT matrix and decision stage by using QSPM. The result of this research shows that the alternative strategy are to maintain and improve the quality of seed product (F1), baglog and oyster mushroom; to improve the quality of human resources of group members in post-harvest handling; forming the partnerships with other groups or associations with baglog makers or mushroom cultivators to achieved the price agreement; cooperation with other groups in the case of synchronization of time to make the baglog and mushroom cultivation so that if there is pest or disease all baglog maker or oyster mushroom grower is not attacked all; increased production efficiency to improve the competitiveness; and saving through cost efficiency. Priority of the strategy obtained in the development of oyster mushroom to maintain and to improve the quality of seed products (F1), baglog (planting medium) and oyster mushroom (STAS: 4.67).
\end{abstract}

Keywords : IFE, EFE, SWOT, QSPM, oyster mushroom

\begin{abstract}
Abstrak :Tujuan penelitian ini adalah menentukan prioritas strategi yang paling efektif untuk diterapkan dalam mengembangkan jamur tiram di Kelompok Tani Aneka Jamur Desa Gondangmanis, Kecamatan Karangpandan, Kabupaten Karanganyar. Metode pemilihan lokasi pada penelitian ini adalah secara purposive (sengaja). Tahapan penelitian meliputi identifikasi faktor internal dan eksternal yang menunjukkan kekuatan, kelemahan, peluang dan ancaman yang dihadapi oleh kelompok tani. Tahap input dilaksanakan dengan membuat matriks IFE dan matriks EFE. Tahap pencocokan menggunakan matriks SWOT dan tahap keputusan menggunakan QSPM. Hasil penelitian menunjukkan alternatif strategi yang diperoleh yaitu mempertahankan dan meningkatkan kualitas produk bibit (F1), baglog dan jamur tiram; meningkatkan kualitas SDM anggota kelompok dalam penanganan pasca panen; membentuk kemitraan dengan kelompok lain atau asosiasi dengan pembuat baglog atau pembudidaya jamur sehingga tercapai kesepakatan harga; kerjasama dengan kelompok lain dalam hal keserempakan waktu untuk membuat baglog dan budidaya jamur sehingga apabila ada hama atau penyakit seluruh pembuat baglog atau pembudidaya jamur tiram tidak terserang semua; peningkatan efisiensi produksi untuk meningkatkan daya saing; dan penghematan melalui efisiensi biaya. Prioritas strategi yang diperoleh dalam pengembangan jamur tiram di kelompok tani Aneka Jamur adalah mempertahankan dan meningkatkan kualitas produk bibit (F1), baglog (media tanam) dan jamur tiram (STAS : 4,67)
\end{abstract}

Kata kunci: IFE, EFE, SWOT, QSPM, jamur tiram 


\section{PENDAHULUAN}

Permintaan konsumen terhadap komoditas jamur tiram yang cukup besar membuat peluang bisnis jamur tiram ini masih terbuka lebar. Bisnis jamur tiram dapat dilakukan mulai dari pengadaan bahan baku atau media baglog jamur, budidaya jamur tiram, pemasaran, dan bisnis jamur olahan.

Bisnis jamur tiram saat ini dan pada masa mendatang masih merupakan bisnis yang memiliki prospek sangat bagus, hal ini dikarenakan permintaan pasar belum dapat terpenuhi oleh produsen.

Besarnya permintaan jamur tiram di pasaran membuat petani memiliki harapan yang besar untuk memperoleh pendapatan yang besar dari hasil budidaya jamur tiram, akan tetapi pada kenyataannya kesejahteraan petani jamur tiram masih jauh dari harapan. Hal ini disebabkan karena kurangnya pengetahuan dan ketrampilan petani dalam mengelola budidaya jamur tiram, kurangnya akses dalam sistem pemasaran, serta kurangnya pengetahuan tentang strategi pengembangan jamur tiram.

Salah satu sentra jamur tiram adalah Kabupaten Karanganyar. Sebagian wilayah di Kabupaten Karanganyar merupakan daerah pegunungan/perbukitan sehingga sangat potensial untuk membudidayakan tanaman sayur-sayuran dimana komoditas jamur termasuk didalamnya. Potensi ini perlu dimanfaatkan untuk mengembangkan produksi jamur khususnya jamur tiram di wilayah Kabupaten Karanganyar (Rochmat dkk, 2012). Pelaku usaha/bisnis jamur tiram di wilayah Karanganyar banyak terdapat daerah Ngargoyoso, Karangpandan, dan Matesih. Daerah pasar yang dituju adalah sekitar Surakarta, Karanganyar dan sekitarnya.

Di daerah Karanganyar terdapat kelompok tani yang mengusahakan jamur tiram mulai dari pembuatan media baglog jamur, budidaya jamur tiram dan pengolahan jamur tiram yaitu kelompok tani “Aneka Jamur” Desa Gondangmanis, Kecamatan Karangpandan. Meskipun demikian produksi jamur masih belum mampu memenuhi permintaan konsumen yang disebabkan oleh berbagai permasalahan yang ada. Beberapa permasalahan yang dapat diidentifikasikan yaitu kurangnya pengetahuan petani dalam budidaya jamur mulai dari persiapan baglog jamur/bibit jamur hingga pada budidaya jamur, permasalahan permodalan,dan lain sebagainya.

Tujuan penelitian ini adalah mengidentifikasi faktor internal dan eksternal yang mempengaruhi pengembangan jamur tiram, menentukan alternatif strategi, dan menentukan prioritas strategi yang efektif diterapkan dalam mengembangkan jamur tiram di Kabupaten Karanganyar.

David (2012), mendefinisikan manajemen strategis sebagai seni dan ilmu untuk merumuskan, mengimplementasikan, dan mengevaluasi keputusan lintas fungsional yang memungkinkan suatu organisasi mencapai sasarannya. Manajemen strategi sebagai suatu proses terdiri dari tiga tahap yaitu: perumusan, implementasi, dan evaluasi strategi.

Teknik-teknik perumusan strategi yang penting dapat diintegrasikan ke dalam kerangka pembuatan keputusan tiga tahap. Tahap 1 dari kerangka perumusan terdiri dari Matrik EFE, Matrik IFE, dan Matrik Profil Kompetitif (Competitive Profil Matrix-CPM) disebut Tahap Masukan (Input Stage). Tahap 1 meringkas informasi masukan dasar yang diperlukan untuk merumuskan strategi.

Tahap 2 disebut Tahap Pencocokan (Matching Stage), fokus pada upaya menghasilkan strategi alternatif yang dapat dijalankan (feasible) dengan memadukan faktor-faktor eksternal dan internal. Teknikteknik tahap 2 terdiri dari Matriks Strengths Weaknesses Opportunities Threats (SWOT) atau Ancaman Peluang Kelemahan Kekuatan, Matriks BCG (Boston ConsultingGroup), Matriks Internal Eksternal (IE), dan Matriks Grand Strategy (Strategi Induk).

Tahap 3 disebut Tahap Keputusan (Decision Stage), menggunakan satu macam teknik, yaitu Quantitative Strategic Planning Matrix (QSPM). QSPM menggunakan informasi masukan dari tahap 1 untuk secara objektif mengevaluasi strategi alternatif dapat dijalankan yang diidentifikasi dalam tahap 2 . QSPM mengungkap daya tarik relatif dari strategi alternatif dan karena itu menjadi dasar objektif untuk memilih strategi spesifik (David, 2012).

Penelitian Taufik (2012), mengenai strategi pengembangan agribisnis sayuran di Sulawasi Selatan dengan menggunakan analisis SWOT memperoleh empat strategi yang perlu dilaksanakan : (1) strategi agresif 
(S-O), memaksimalkan potensi/ kekuatan untuk meraih peluang dengan memanfaatkan teknologi produksi, perluasan lahan dan pangsa pasar, dukungan kebijakan pemerintah, penguatan kelembagaan, dan peningkatan kualitas SDM, (2) strategi diversifikasi (S-T), memaksimalkan potensi/kekuatan untuk mengurangi ancaman yang ada dengan melakukan kegiatan usaha tani yang ramah lingkungan, pemberdayaan penangkar benih, dan penerapan pengendalian hama terpadu (PHT), 3) strategi divestasi (W-O), meminimalkan kelemahan/ hambatan untuk meraih peluang semaksimal mungkin melalui peningkatan produksi/ produktivitas serta mutu produk, penguatan sarana usaha pertanian, diversifikasi, dan pengaturan pola tanam sesuai permintaan pasar, serta 4) strategi survival (WT), meminimalkan kelemahan dan hambatan untuk mengatasi ancaman dengan meningkatkan efisiensi biaya produksi, memperluas informasi pasar, dan mengoptimalkan pemakaian input kimia.

\section{METODE PENELITIAN}

Metode pemilihan lokasi pada penelitian ini adalah secara purposive (sengaja) yaitu Kelompok Tani Aneka Desa Gondangmanis, Kecamatan Karangpandan, Kab. Karanganyar. Penelitian dimulai dari bulan April sampai September 2017.

1. Metode Penentuan Responden

a. Penentuan informan untuk tahap 1 : identifikasi faktor internal dan eksternal. Informan dipilih secara purposive (sengaja) yaitu pengurus Kelompok Tani Aneka Jamur (Ketua, Sekretaris dan Bendahara), Petugas Penyuluh Lapangan (PPL) Kec. Karangpandan, Pengurus Masyarakat Agribisnis Jamur Indonesia (MAJI) Karanganyar.

b. Penentuan informan untuk tahap 2 : penilaian bobot dalam matriks SWOT. Informan ahli dipilih secara purposive (sengaja) yaitu pengurus kelompok tani Aneka Jamur, Penyuluh Lapangan (PPL) Kec. Karangpandan, Pengurus Masyarakat Agribisnis Jamur Indonesia (MAJI) Karanganyar.

c. Penentuan informan untuk tahap 3 : penilaian matriks QSPM.
Informan dipilih secara purposive (sengaja) yaitu ketua kelompok tani Aneka Jamur.

2. Jenis dan Sumber Data

Data yang digunakan dalam penelitian ini adalah data primer dan data sekunder. Data primer dalam penelitian ini diperoleh langsung dari responden dalam penelitian ini melalui wawancara dan FGD (Focus Group Discussion). Data sekunder diperoleh dari literatur, Dinas Pertanian Kabupaten, Badan Pusat Statistik (BPS), dan monografi desa/kecamatan.

3. Teknik Pengumpulan Data

Dilakukan dengan observasi, wawancara, diskusi (FGD), dan pencatatan.

4. Metode Analisis Data

a. Analisis deskriptif

b. Analisis faktor internal dan faktor eksternal

Faktor internal menganalisis kekuatan dan kelemahan, sedangkan faktor eksternal menganalisis ancaman dan peluang yang dihadapi oleh kelompok tani. Setelah faktor-faktor tersebut dapat diidentifikasi kemudian memasukkan faktor tersebut dalam matrik IFE dan matrik EFE.

c. Alternatif Strategi

Analisis SWOT digambarkan dalam Matriks SWOT dengan 4 kemungkinan alternatif strategi, yaitu strategi kekuatan-peluang (S-O strategi), strategi kelemahan-peluang (W-O strategi), strategi kekuatan-ancaman (S-T strategi), dan strategi kelemahan-ancaman (W-T strategi).

d. Prioritas Strategi

Menentukan prioritas strategi menggunakan Matrik QSPM. Alternatif strategi yang memiliki nilai total terbesar pada Matrik QSPM merupakan strategi yang paling baik.

\section{HASIL DAN PEMBAHASAN}

Dari hasil analisis lingkungan internal diperoleh kekuatan dan kelemahan kelompok tani Aneka Jamur (Tabel 1). Lingkungan eksternal kelompok yang berupa peluang dan ancaman dapat dilihat pada tabel 2

Berdasarkan analisis matriks IFE pada tabel 1 menunjukkan skor 2.92 yang memiliki 
arti bahwa kelompok tani Aneka Jamur pada posisi yang kuat. Berdasarkan David (2012), menyatakan bahwa jika skor rata-rata dibawah 2.5 berarti organisasi pada posisi yang lemah secara internal, sedangkan skor diatas 2.5 mengindikasikan pada posisi internal yang kuat.

Tabel 2 menunjukkan bahwa peluang terbesar yaitu pangsa pasar yang masih luas dan permintaan baglog jamur yang cukup tinggi dengan skor 0,48. Kelompok tani Aneka Jamur mampu memproduksi sekitar 40.000 baglog setiap bulannya, padahal permintaan baglog dari pembudidaya jamur sekitar 60.000-75.000 baglog setiap bulan. Ancaman utama yang harus diwaspadai yaitu kompetisi pembuat baglog sangat tinggi dengan skor 0,30.

Analisis matriks SWOT menggunakan hasil analisis yang didapatkan dari matriks IFE dan EFE. Matriks IFE mengidentifikasi faktor internal yang mencakup kekuatan dan kelemahan, sedangkan matriks EFE mengidentifikasi faktor eksternal yang mencakup peluang dan ancaman.

Alternatif strategi berdasarkan matriks SWOT yaitu :

a. Strategi SO (Strength-Opportunity) adalah strategi yang menggunakan kekuatan internal untuk memanfaatkan peluang eksternal. Alternatif strategi SO yang dapat dirumuskan adalah :

1. Mempertahankan dan meningkatkan kualitas produk bibit (F1), baglog (media tanam) dan jamur tiram. Kompetisi terjadi dalam hal mutu, waktu, dan biaya. Petani jamur menginginkan baglog dengan mutu yang baik, pengiriman yang tepat waktu, dan harga yang murah (Maharani $d k k, 2016$ ).

2. Meningkatkan kualitas SDM anggota kelompok dalam penanganan pasca panen.

Alternatif strategi ini dimaksudkan bahwa anggota kelompok mampu memproduksi dan memasarkan hasil olahan jamur tiram apabila panen jamur tiram berlimpah, sehingga dengan produk olahan mampu memberikan nilai tambah dari jamur tiram.

b. Strategi WO (Weakness-Opportunity) adalah strategi untuk meminimalkan kelemahan yang ada untuk memanfaatkan peluang eksternal. Strategi WO yang dapat dirumuskan adalah :

1. Peningkatan efisiensi produksi untuk meningkatkan daya saing.

c. Strategi ST (Strength-Threat) adalah strategi untuk mengoptimalkan kekuatan internal yang dimiliki dalam menghindari ancaman. Strategi ST yang dapat dirumuskan adalah :

1. Membentuk kemitraan dengan kelompok lain atau asosiasi dengan pembuat baglog/pembudidaya jamur sehingga mampu mencapai kesepakatan harga.

2. Kerjasama dengan kelompok lain dalam hal keserempakan waktu untuk membuat baglog dan budidaya jamur, sehingga apabila ada hama atau penyakit seluruh pembuat baglog atau pembudidaya jamur tiram tidak terserang semua.

\section{d. Strategi WT}

Strategi WT adalah strategi defensif untuk meminimalkan kelemahan internal dan menghindari ancaman eksternal. Strategi yang dapat dirumuskan yaitu : Penghematan melalui efisiensi biaya.

Dari enam alternatif strategi yang diperoleh melalui analisis SWOT, maka dipilih tiga alternatif strategi untuk analisis QSPM. Alternatif strategi yang dipilih oleh ketua kelompok Aneka Jamur yaitu :

1. Mempertahankan dan meningkatkan kualitas produk bibit (F1), baglog (media tanam) dan jamur tiram.

2. Membentuk kemitraan dengan kelompok lain atau asosiasi dengan pembuat baglog/pembudidaya jamur sehingga mampu mencapai kesepakatan harga.

3. Peningkatan efisiensi produksi untuk meningkatkan daya saing.

Adapun alat analisis yang digunakan pada tahap pengambilan keputusan ini adalah Matriks Perencanaan Strategi Kuantitatif (Quantitative Strategic Planning MatrixQSPM).

Secara konsep, QSPM menentukan daya tarik relatif dari berbagai strategi berdasarkan seberapa jauh faktor strategis internal dan eksternal dimanfaatkan atau diperbaiki. Nilai AS (Attrativeness Score) menunjukkan daya tarik masing-masing strategi terhadap faktor kunci internal dan eksternal perusahaan. Nilai 
AS diperoleh melalui kuisioner yang ditujukan kepada Ketua Kelompok Tani Aneka Jamur dengan pertimbangan bahwa yang paling mengetahui dan mengerti segala sesuatu yang dibutuhkan oleh kelompok tani.

Nilai TAS (Total Attrativeness Scores) responden diperoleh dari hasil perkalian antara bobot rata-rata dan nilai AS dari setiap faktor kunci strategis. Kemudian dilanjutkan perhitungan nilai STAS (Sum Total Attrativeness Scores) responden dengan cara menjumlahkan seluruh nilai TAS dari masing- masing faktor internal dan eksternal. Hasil analisis QSPM dapat dilihat pada tabel 3.

Analisis matriks QSPM diperoleh prioritas strategi sebagai berikut : mempertahankan dan meningkatkan kualitas produk bibit (F1), baglog (media tanam) dan jamur tiram (STAS : 4,67), peningkatan efisiensi produksi untuk meningkatkan daya saing (STAS : 3,01), dan membentuk kemitraan dengan kelompok lain atau asosiasi dengan pembuat baglog/pembudidaya jamur sehingga mampu mencapai kesepakatan harga (STAS : 2,65).

Tabel 1. Analisis Matriks IFE

\begin{tabular}{|c|c|c|c|c|}
\hline No & Uraian & Bobot & Peringkat & $\begin{array}{l}\text { Skor Bobot } \\
\text { Peringkat }\end{array}$ \\
\hline & \multicolumn{4}{|l|}{ KEKUATAN } \\
\hline 1 & \multirow{2}{*}{$\begin{array}{l}\text { Pertemuan kelompok rutin dilaksanakan } \\
\text { Ketua kelompok disiplin, mampu mengelola kelompok } \\
\text { dengan baik, }\end{array}$} & 0.06 & 3 & 0.18 \\
\hline 2 & & 0.07 & 3 & 0.21 \\
\hline 3 & \multirow{2}{*}{$\begin{array}{l}\text { Kerjasama antar anggota kelompok sangat baik/kompak } \\
\text { Ketua kelompok berpengalaman, sering menjadi } \\
\text { narasumber di berbagai pelatihan dan media elektronik } \\
\text { lainnya }\end{array}$} & 0.05 & 3 & 0.15 \\
\hline 4 & & 0.07 & 4 & 0.28 \\
\hline 5 & \multirow{3}{*}{$\begin{array}{l}\text { SDM anggota kelompok terlatih } \\
\text { Lingkungan tumbuh dan iklim mendukung } \\
\text { pertumbuhan jamur } \\
\text { Sudah mampu membuat benih dari kultur jaringan, } \\
\text { baglog juga sudah mampu membuat sendiri }\end{array}$} & 0.05 & 3 & 0.15 \\
\hline 6 & & 0.05 & 3 & 0.15 \\
\hline 7 & & 0.07 & 4 & 0.28 \\
\hline 8 & \multirow{2}{*}{$\begin{array}{l}\text { Kualitas produksi jamur tiram baik } \\
\text { Perputaran modal untuk budidaya jamur tiram cepat } \\
\text { kembali }\end{array}$} & 0.07 & 4 & 0.28 \\
\hline 9 & & 0.06 & 3 & 0.18 \\
\hline 10 & Harga jamur tiram relatif stabil & 0.06 & 4 & 0.24 \\
\hline 11 & Jamur tiram dapat dipanen setiap hari & 0.07 & 3 & 0.21 \\
\hline & $\begin{array}{l}\text { Menyerap tenaga kerja dari sekitar, sehingga } \\
\text { mengurangi pengangguran, serta meningkatkan } \\
\text { pendapatan ibu rumah tangga }\end{array}$ & 0.07 & 4 & 0.28 \\
\hline 12 & \multicolumn{4}{|l|}{ KELEMAHAN } \\
\hline 13 & Modal terbatas & 0.04 & 1 & 0.04 \\
\hline 14 & BER masih rendah, rata-rata 3-5 ons per baglog & 0.04 & 2 & 0.08 \\
\hline 15 & Panen sulit diprediksi waktunya & 0.04 & 1 & 0.04 \\
\hline 16 & Skala usaha anggota masih kecil & 0.04 & 1 & 0.04 \\
\hline 17 & Tempat terpencar-pencar & 0.04 & 2 & 0.08 \\
\hline 18 & $\begin{array}{l}\text { Kondisi saat ini, baglog seringkali terserang hama dan } \\
\text { penyakit, sehingga jamur tidak tumbuh }\end{array}$ & 0.04 & 1 & 0.04 \\
\hline & Total & 1.00 & & 2.92 \\
\hline
\end{tabular}


Tabel 2. Analisis Matriks EFE

\begin{tabular}{|c|c|c|c|c|}
\hline No & Uraian & Bobot & Peringkat & $\begin{array}{l}\text { Skor Bobot } \\
\text { Peringkat }\end{array}$ \\
\hline & PELUANG & & & \\
\hline 1 & Pangsa pasar masih luas & 0.12 & 4 & 0.48 \\
\hline 2 & $\begin{array}{l}\text { Masyarakat mulai mengenal produk makanan dari jamur } \\
\text { tiram, bergizi dan non kolesterol }\end{array}$ & 0.08 & 4 & 0.32 \\
\hline 3 & Permintaan baglog cukup tinggi & 0.12 & 4 & 0.48 \\
\hline 4 & Harga produk jamur cukup tinggi & 0.10 & 3 & 0.30 \\
\hline 5 & $\begin{array}{l}\text { Hasil olahan jamur bisa dikembangkan dalam aneka } \\
\text { olahan jamur, misal keripik, nugget, bakso, dan lain-lain }\end{array}$ & 0.10 & 3 & 0.30 \\
\hline 6 & $\begin{array}{l}\text { ANCAMAN } \\
\text { Bahan baku baglog jamur/serbuk gergaji semakin sulit } \\
\text { diperoleh }\end{array}$ & 0.09 & 3 & 0.27 \\
\hline 7 & Kompetisi pembuat baglog sangat tinggi & 0.10 & 3 & 0.30 \\
\hline 8 & $\begin{array}{l}\text { Kompetisi antar kelompok atau pembudidaya baglog } \\
\text { sangat ketat } \\
\text { Di tingkat petani/pembudidaya jamur, seringkali baglog }\end{array}$ & 0.09 & 2 & 0.18 \\
\hline 9 & & 0.05 & 3 & 0.15 \\
\hline 10 & $\begin{array}{l}\text { bersamaan maka harga jamur rendah. } \\
\text { Ketidaktelitian dan lingkungan yang tidak/kurang hygienis } \\
\text { untuk pembuat baglog dan pembudidaya jamur tiram } \\
\text { membuat jamur tidak berproduksi maksimal atau Resiko }\end{array}$ & 0.06 & 2 & 0.12 \\
\hline \multirow[t]{2}{*}{11} & tinggi di tingkat pembuat baglog dan pembudidaya jamur & 0.08 & 3 & 0.24 \\
\hline & Total & 1.00 & & 3.14 \\
\hline
\end{tabular}

Tabel 3. Analisis Matriks QSPM

\begin{tabular}{|c|c|c|c|c|c|c|c|}
\hline \multicolumn{2}{|l|}{ Alternatif Strategi } & \multicolumn{2}{|l|}{1} & \multirow{2}{*}{\multicolumn{2}{|c|}{\begin{tabular}{l}
\multicolumn{1}{c}{2} \\
Membentuk kemitraan \\
dengan kelompok lain \\
atau asosiasi dengan \\
pembuat \\
baglog/pembudidaya \\
jamur sehingga mampu \\
mencapai kesepakatan \\
harga
\end{tabular}}} & \multicolumn{2}{|l|}{3} \\
\hline & & \multicolumn{2}{|c|}{$\begin{array}{l}\text { Mempertahankan dan } \\
\text { meningkatkan kualitas } \\
\text { produk bibit (F1), baglog } \\
\text { (media tanam) dan jamur } \\
\text { tiram }\end{array}$} & & & \multicolumn{2}{|c|}{$\begin{array}{l}\text { Peningkatan } \\
\text { efisiensi produksi } \\
\text { untuk } \\
\text { meningkatkan } \\
\text { daya saing } \\
\end{array}$} \\
\hline Faktor-faktor Utama & Bobot & AS & TAS & AS & TAS & AS & TAS \\
\hline \multicolumn{8}{|l|}{ Peluang } \\
\hline $\begin{array}{l}\text { 1. Pangsa pasar masih luas } \\
\text { 2. Masyarakat mulai mengenal } \\
\text { produk makanan dari jamur } \\
\text { tiram, bergizi dan non kolesterol }\end{array}$ & 0.12 & 4 & 0.48 & 3 & 0.36 & 2 & 0.24 \\
\hline 3.Permintaan baglog cukup tinggi & 0.12 & 4 & 0.48 & 2 & 0.24 & 3 & 0.36 \\
\hline $\begin{array}{l}\text { 4. Harga produk jamur cukup tinggi } \\
\text { 5. Hasil olahan jamur bisa } \\
\text { dikembangkan dalam aneka } \\
\text { olahan jamur, misal keripik, } \\
\text { nugget, bakso, dll }\end{array}$ & 0.10 & 4 & 0.4 & 3 & 0.3 & 2 & 0.2 \\
\hline
\end{tabular}


Ancaman

1. Bahan baku baglog

jamur/serbuk gergaji semakin sulit diperoleh

2. Kompetisi pembuat baglog sangat tinggi

0.10

0.4

2

0.2

0.3

3. Kompetisi antar kelompok atau pembudidaya baglog sangat ketat

4. Di tingkat petani/pembudidaya jamur, seringkali baglog jamur sulit didapat sehingga tidak ada kepastian budidaya

5. Waktu panen yang sulit diprediksi sehingga apabila panen bersamaan maka harga jamur rendah.

6. Ketidaktelitian dan lingkungan yang tidak/kurang hygienis untuk pembuat baglog dan pembudidaya jamur tiram membuat jamur tidak berproduksi maksimal atau Resiko tinggi di tingkat pembuat baglog dan pembudidaya jamur 0.08 4 0.32 0.08 2 0.16 Total 1.00

Kekuatan

1. Pertemuan kelompok rutin dilaksanakan

0.06

3

0.19

4

0.26

2

. Ketua kelompok disiplin, mampu mengelola kelompok dengan baik,

0.07

0.27

3

0.2

2

kelompok sangat baik/kompak

0.05

3

0.16

4

0.21

sering menjadi narasumber di berbagai pelatihan dan media elektronik lainnya

5. SDM anggota kelompok terlatih

7. Sudah mampu membuat benih dari kultur jaringan, baglog juga sudah mampu membuat sendiri

9. Perputaran modal untuk budidaya jamur tiram cepat kembali

10. Harga jamur tiram relatif stabil

11. Jamur tiram dapat dipanen setiap hari

12. Menyerap tenaga kerja dari sekitar, sehingga mengurangi pengangguran, serta meningkatkan pendapatan ibu rumah tangga 


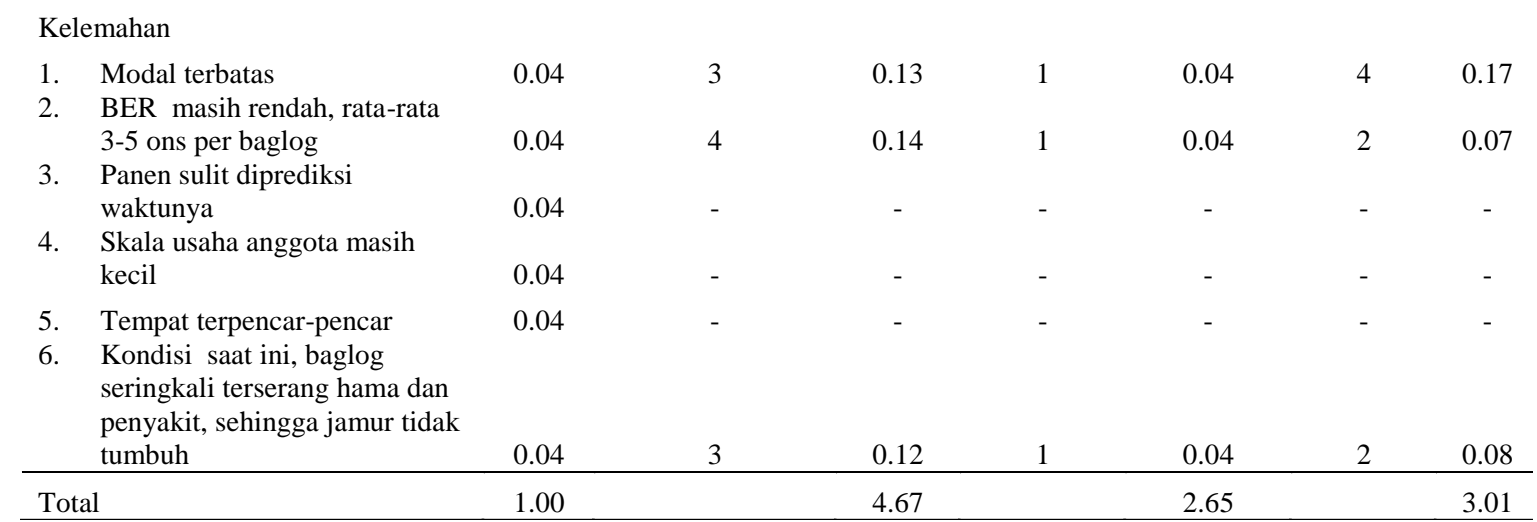

\section{KESIMPULAN DAN SARAN}

\section{Kesimpulan}

a. Alternatif strategi yang diperoleh yaitu mempertahankan dan meningkatkan kualitas produk bibit (F1) dan baglog serta jamur tiram; meningkatkan kualitas SDM anggota kelompok dalam penanganan pasca panen; membentuk kemitraan dengan kelompok lain atau asosiasi dengan pembuat baglog atau pembudidaya jamur sehingga tercapai kesepakatan harga; kerjasama dengan kelompok lain dalam hal keserempakan waktu untuk membuat baglog dan budidaya jamur sehingga apabila ada hama atau penyakit seluruh pembuat baglog atau pembudidaya jamur tiram tidak terserang semua; peningkatan efisiensi produksi untuk meningkatkan daya saing; dan penghematan melalui efisiensi biaya.

b. Prioritas strategi yang dapat dikembangkan untuk kelompok tani Aneka jamur adalah mempertahankan dan meningkatkan kualitas produk bibit (F1) dan baglog (media tanam) serta jamur tiram.

\section{Saran}

Meningkatkan ketrampilan anggota kelompok tani untuk pengelolaan pasca panen jamur tiram sehingga mampu memberikan nilai tambah dan meningkatkan pendapatan anggota kelompok.

\section{DAFTAR PUSTAKA}

David, F.R. 2012. Manajemen Strategis Konsep. Edisi 12. Jakarta. Salemba Empat.

Maharani N.M.K., Iga Oka S., dan I Nyoman Gede Ustriyana. 2016. Peningkatan Efisiensi Produksi Baglog Melalui Percepatan Waktu Siklus Produksi di Usaha Lancar Abadi Pendekatan Critical Path Method. E-Jurnal Agribisnis dan Agrowisata. 5 (1) Januari 2016.

Rohmat, F., Erlyna Wida Riptanti, Suprapto. 2012. Analisis Efisiensi dan Titik Impas Usahatani Jamur Tiram Di Kabupaten Karanganyar. Skripsi Program Studi Agribisnis Fakultas Pertanian. Universitas Sebelas Maret Surakarta.

Taufik, M. 2012. Strategi Pengembangan Agribisnis Sayuran Di Sulawesi Selatan. Jurnal Litbang Pertanian 31 (2) :43-49.

Widowati, R., Muhamad R., dan Dhyani N. P. 2015. Teknologi Pengolahan Hasil Jamur Tiram serta Analisis Usaha Taninya di Kota Balikpapan, Provinsi Kalimantan Timur. Prosiding Seminar Nasional Masy Biodiv Indon. 1(2) : 337-342. 